\title{
Using Microphone Technology to Improve Speech Perception in Noise in Children with Cochlear Implants
}

DOI: $10.3766 /$ jaaa.17035

\author{
Patti M. Johnstone* \\ Kristen E. T. Mills* \\ Elizabeth Humphrey* \\ Kelly R. Yeager* \\ Emily Jones* \\ Kelly McElligott* \\ Amy Pierce* \\ Smita Agrawal $\uparrow$ \\ Crista Froeling; \\ John P. Little§
}

\begin{abstract}
Background: Cochlear implant $(\mathrm{Cl})$ users are affected more than their normal hearing $(\mathrm{NH})$ peers by the negative consequences of background noise on speech understanding. Research has shown that adult $\mathrm{Cl}$ users can improve their speech recognition in challenging listening environments by using dualmicrophone beamformers, such as adaptive directional microphones (ADMs) and wireless remote microphones (RMs). The suitability of these microphone technologies for use in children with Cls is not well-understood nor widely accepted.
\end{abstract}

Purpose: To assess the benefit of ADM or RM technology on speech perception in background noise in children and adolescents with cochlear implants (Cls) with no previous or current use of ADM or RM.

Research Design: Mixed, repeated measures design.

Study Sample: Twenty (20) children, ten (10) Cl users (mean age 14.3 yrs) who used Advanced Bionics HiRes90K implants with research Naida processors, and ten (10) NH age-matched controls participated in this prospective study.

Intervention: $\mathrm{Cl}$ users listened with an ear-canal level microphone, T-Mic (TM), an ADM, and a wireless RM at different audio-mixing ratios. Speech understanding with five microphone settings (TM 100\%, ADM, RM + TM 50/50, RM + TM 75/25, RM 100\%) was evaluated in quiet and in noise.

Data Collection and Analysis: Speech perception ability was measured using children's spondee words to obtain a speech recognition threshold for $80 \%$ accuracy (SRT80\%) in 20-talker babble where the listener sat in a sound booth $1 \mathrm{~m}\left(3.28^{\prime}\right)$ from the target speech (front) and noise (behind) to test five microphone settings (TM 100\%, ADM, RM + TM 50/50, RM + TM 75/25, RM 100\%). Group performanceintensity functions were computed for each listening condition to show the effects of microphone configuration with respect to signal-to-noise ratio (SNR). A difference score (Cl Group minus NH Group) was computed to show the effect of microphone technology at different $\mathrm{SNR}$ s relative to $\mathrm{NH}$. Statistical analysis

*Department of Audiology and Speech Pathology, College of Health Professions, University of Tennessee Health Science Center, Knoxville, TN; $†$ Advanced Bionics, LLC, Valencia, CA; $¥$ Tennessee School for the Deaf, Knoxville, TN; §Children’s Ear, Nose and Throat Specialists, Children’s Hospital Medical Office Building, Knoxville, TN

Corresponding author: Patti M. Johnstone, Department of Audiology and Speech Pathology, College of Health Professions, University of Tennessee Health Science Center, Knoxville, TN; Email: pjohnst1@uthsc.edu

This research was supported by Advanced Bionics, LLC to Patti M. Johnstone.

Portions of this article were presented orally at the Conference on Implantable Auditory Prostheses, Lake Tahoe, CA, 2015; the Conference for the American Cochlear Implant Alliance, Washington DC, 2015; and the 14th International Conference on Cochlear Implants, Toronto, Ontario, Canada, 2016. 
using a repeated-measures analysis of variance evaluated the effects of the microphone configurations on SRT80\% and performance at SNRs. Between-groups analysis of variance was used to compare the $\mathrm{Cl}$ group with the $\mathrm{NH}$ group.

Results: The speech recognition was significantly poorer for children with $\mathrm{Cl}$ than children with $\mathrm{NH}$ in quiet and in noise when using the TM alone. Adding the ADM or RM provided a significant improvement in speech recognition for the $\mathrm{Cl}$ group over use of the $\mathrm{TM}$ alone in noise (mean $\mathrm{dB}$ advantage ranged from 5.8 for ADM to 16 for RM100). When children with $\mathrm{Cl}$ used the RM75 or RM100 in background babble, speech recognition was not statistically different from the group with $\mathrm{NH}$.

Conclusion: Speech recognition in noise performance improved with the use of ADM and RM100 or $\mathrm{RM} 75$ over TM-only for children with Cls. Alhough children with $\mathrm{Cl}$ remain at a disadvantage as compared with $\mathrm{NH}$ children in quiet and more favorable SNRs, microphone technology can enhance performance for some children with $\mathrm{Cl}$ to match that of $\mathrm{NH}$ peers in contexts with negative SNRs.

Key Words: children, cochlear implant, microphone technology, remote microphones

Abbreviations: $\mathrm{ADM}=$ adaptive directional microphone; ANOVA = analysis of variance; $\mathrm{Cl}=$ cochlear implant; CRISP = children's realistic index of speech perception; $\mathrm{DM}=$ directional microphone; $\mathrm{FM}=$ frequency modulated; $\mathrm{NH}$ = normal hearing; $\mathrm{RM}$ = remote microphone; $\mathrm{SNR}$ = signal-to-noise ratio; $\mathrm{SRT}=$ speech recognition threshold; SHARP $=$ situational hearing aid response profile; $\mathrm{TM}=\mathrm{T}$-mic

\section{INTRODUCTION}

$\mathrm{C}$ hildren have difficulty understanding what they cannot hear clearly, a particularly problematic fact among young children with impaired hearing (Smaldino and Crandell, 1999; Crandell and Smaldino, 2000). Research has consistently shown that children with impaired hearing are at a distinct disadvatnatge for speech understanding in quiet as well as in noisy environments when compared with normal hearing $(\mathrm{NH})$ peers (Finitzo-Hieber and Tillman, 1978; Crandell, 1993; Schafer and Thibodeau, 2006).

Children with impaired hearing, such as their $\mathrm{NH}$ peers, spend many hours in school. Classrooms, however, are notoriously noisy places. In early studies, the range of background noise typical of classrooms was reported as 53-74 dB SPL, with noise levels in occupied public school classrooms averaging $60 \mathrm{~dB}$ SPL (Pearsons et al, 1977; Olsen, 1998). In a recent study, A-weighted sound measurements of the activity noise levels during elementary and middle school class lessons averaged $57 \mathrm{dBA}$, with input ranging from 42 to $67 \mathrm{dBA}$ (Lyberg Åhlander et al, 2014).

Recent studies have also shown that the level of the teacher's voice changes too. Teachers rely heavily on their voices to deliver educational material, overcome large talker-to-listener distances, manage classroom acoustics, and to deal with student behavior (Schmidt and Morrow, 2016). The teaching tasks at elementary and middle schools can vary from soft facilitating talk, to singing, reading aloud, lecturing, and shouting during recess or gym class (Lyberg Åhlander et al, 2014). As a result, the teachers' vocal intensity levels during any given workday can range from 50 to $100+\mathrm{dB}$ SPL with median levels between 55 and $75 \mathrm{~dB}$ SPL (Lyberg Åhlander et al, 2014; Titze and Hunter, 2015). The recommended signal- to-noise ratio (SNR) for classrooms is $+15 \mathrm{~dB}$ or greater (Crandell and Smaldino, 2000), however, average SNRs in most learning environments are between $-6 \mathrm{~dB}$ and +6 dB (Olsen, 1998, Knecht et al, 2002; Nelson et al, 2008).

Research has shown that children with ear-level hearing aids (HAs) can meet many listening challenges in classroom settings by using microphone technology. For example, directional microphones (DMs) (for a recent review see McCreery et al, 2012; also see Ricketts et al, 2010; Pittman and Hiipakka, 2013); adaptive beamforming directional microphones (ADMs) (Ricketts and Picou, 2013; Ricketts et al, 2017; Wolfe et al, 2017); and remote microphones (RMs) (e.g., Lewis and Eiten, 2011; Norrix et al, 2016).

Although $\mathrm{DM}, \mathrm{ADM}$, and RM were originally developed to limit the negative effects of noise on speech understanding for HA users in challenging listening environments, they are now incorporated into cochlear implants (CIs). DMs allow input from sound sources in front of the listener while simultaneously reducing amplification for sound sources at the sides and behind the listener. Directionality can be achieved on Advanced Bionics CI devices in two ways. First, by using the T-mic (TM), a single microphone, located at the opening of the ear canal. Or second, by using an ADM system such as UltraZoom, which consists of dual-microphones at different locations on the sound processor that facilitate beamforming. ADM automatically switches the directional pattern based on the location of the predominant noise source.

Although DM and ADM technologies are effective in reducing background noise for CI users, they may not sufficiently allow for satisfactory communication in many real-world listening contexts (James et al, 2002; Dawson et al, 2004; 2011; Wolfe et al, 2009; Gifford and Revit, 2010). Remote microphone (RM) systems offer the opportunity to further enhance the SNR by providing direct 
audio input to the CI. The most widely studied RM system used by children is the frequency modulated (FM) system which has a long history of use in educational contexts (e.g., Hawkins, 1984; Lewis, 1994; 2008; Boothroyd and Iglehart, 1998; Anderson and Goldstein, 2004; Anderson et al, 2005). Another option for RM, and the type of RM used in the current study, uses the Bluetooth ${ }^{\circledR}$ codec to transmit audio directly to a "streamer," worn around the neck of the CI user. The streamer translates the Bluetooth ${ }^{\circledR}$ signal to a proprietary wireless, short range, nearfield magnetic induction signal that is sent to the CI (Rodemerk and Galster, 2015). The RM can be worn by a specific talker or placed strategically making the voice of the specific talker more intense compared with the signals at the CI user.

Another desireable feature of RM systems is the ability to simultaneously activate the CI microphone in addition to the RM, allowing the CI user to hear his or her own voice and the voices of those nearby, in addition to the person at the RM. The contribution of the RM verus the CI microphone can be adjusted via mixing ratios. It is not known how these mixing ratios affect speech understanding in pediatric CI users. Early FM research with pediatric HA users revealed a significant degradation of speech recognition thresholds (SRTs) in noise in RM + HA microphone conditions, when compared with RM-only, that did not differ significantly from HA-only (e.g., Hawkins, 1984; Fabry, 1994). However, a more recent study that assessed four different RM systems (Norrix et al, 2016) showed a significant improvement in speech recognition threshold (SRT) with RM + HA microphone cofigurations over HA-only for pediatric listeners with impaired hearing.

The use of DM, ADM, and RM technology in adults with CI devices has been found to significantly improve speech understanding when listening in challenging acoustic environments (Gifford and Rivet, 2010; Buechner et al, 2014; Mauger et al, 2014; Geißler et al, 2015; Kolberg et al, 2015; Wolfe, Morais, and Schafer, 2015; Wolfe, Morais, Schafer, et al, 2015; Vroegop et al, 2017). Results from DM, ADM, and RM studies in adults with CI may not apply to a pediatric population with CI, therefore, the suitability of these microphone systems for use in children and adolescents with CI is not well-understood nor widely accepted (Plasmans et al, 2016). Children, unlike adults, undergo ongoing auditory and language skills development while communicating in the acoustically complex environments in which they must listen and learn. Because children generally experience greater degradation in speech understanding from background noise than adults (e.g., Hall et al, 2002; Johnstone and Litovsky, 2006; Baker et al, 2014), the degree to which the negative consequences of background noise can be limited by RM may have a greater impact on how children with CI can function in noisy environments than an adult population with CI.

The present study sought to investigate the effect of $\mathrm{TM}, \mathrm{ADM}$, and RM technology on SRT in background noise, in school-age children at a short distance $(1 \mathrm{~m} /$ $3.28^{\prime}$ ) from the talker. Participants identified spondee words presented in background babble while listening under TM, ADM, and RM conditions. For RM conditions, various mixing ratios were used where the signal was transmitted through the RM and TM with equal emphasis. For instance, a 50/50 mixing ratio, half of the signal was transmitted through the RM and the other $50 \%$ was transmitted through the TM. Using $\mathrm{RM}+\mathrm{TM}$ mixing ratios of 50/50 (RM50), 75/50 (RM75), and 100/0 (RM100) allowed us to better understand which setting may be optimal for listening with RM technology in children while in noise and also provided a comparison with performance using the $\mathrm{ADM}$.

\section{METHODS}

\section{Participants}

Twenty pediatric native speakers of American English with no known cognitive or learning deficits participated in the study. Ten children (mean age $14.3 \mathrm{yrs} /$ SD 4.72) were recipients of at least one Advanced Bionics Corporation HiRes90K and/or CII cochlear implant. All of the children used TM at home. One child (participant AAP) used a RM (Roger Pen) at school. The other nine participants had no experience with FM, ADM, or RM at home or at school. They all had a history of prelingual onset of deafness and had at least six months of experience with their CI before participation. One child (participant AAV) attended a residential school for the deaf and used total communication, and nine were mainstreamed in public or private schools and used auditory-oral communication. Demographic and hearing history for each participant with a CI is displayed in Table 1 . The remaining 10 participants were typicallydeveloping children (mean age $14.2 \mathrm{yrs} / \mathrm{SD}$ 4.8) with $\mathrm{NH}$ sensitivity, chronologically age-matched to the CI group (mean age 14.3 yrs/SD 4.7). The $\mathrm{NH}$ participants had thresholds at or below $20 \mathrm{~dB}$ HL at 500, 1000, 2000, and $4000 \mathrm{~Hz}$ bilaterally. All testing procedures and materials were approved by the Institutional Review Board at the University of Tennessee Health Science Center before the onset of data collection.

\section{Stimuli and Test Protocols}

The same standard-issue research Naida CI Q70 (Advanced Bionics, Valencia, CA; Sonova, Stäfa, Switzerland) processor was used for testing all participants with CIs. The participant's preferred map from their personal CI was transferred to the research Naida CI Q70 processor. ClearVoice was set to medium for all participants to isolate performance with microphone configuration alone. Five programs that corresponded to five different microphone configurations were created 
Table 1. Participant Demographic Information

\begin{tabular}{|c|c|c|c|c|c|c|c|}
\hline \multirow{2}{*}{$\begin{array}{l}\text { Participant } \\
\text { Code }\end{array}$} & \multirow{2}{*}{$\begin{array}{c}\text { Age } \\
\text { (yrs, mo) }\end{array}$} & \multirow{2}{*}{$\begin{array}{l}\text { Implanted } \\
\text { Ear }\end{array}$} & \multirow[b]{2}{*}{ Etiology } & \multicolumn{2}{|c|}{ Duration of $\mathrm{Cl}$ Use (yrs, mo) } & \multirow{2}{*}{ Implant Model } & \multirow[t]{2}{*}{$\begin{array}{c}\text { Personal } \\
\text { Processor Type }\end{array}$} \\
\hline & & & & Right Ear & Left Ear & & \\
\hline$\overline{\mathrm{AAA}}$ & 19,07 & Left & Unknown & - & 06,04 & HiRes 90K & Naida CI Q 70 \\
\hline$A A B$ & 17,08 & Left & $\begin{array}{l}\text { Unknown; } \\
\text { congenital }\end{array}$ & - & 10,05 & HiRes $90 \mathrm{~K}$ & Naida CI Q 70 \\
\hline$A A D$ & 19,06 & Bilateral & Unknown & 07,07 & 12,02 & HiRes $90 \mathrm{~K}$ & Naida CI Q 70 \\
\hline AAF & 14,11 & Bilateral & $\begin{array}{l}\text { Auditory neuropathy; } \\
\text { congenital }\end{array}$ & 11,05 & 03,05 & HiRes $90 \mathrm{~K}$ & Naida CI Q 70 \\
\hline $\mathrm{AAH}$ & 06,00 & Bilateral & Unknown; congenital & 00,06 & 01,00 & $\begin{array}{l}\text { HiRes } 90 \mathrm{~K} \\
\text { Advantage }\end{array}$ & Naida CI Q 70 \\
\hline$A A P^{*}$ & 16,09 & Left & $\begin{array}{r}\text { Connexin 26; } \\
\text { congenital }\end{array}$ & 00,02 & 03,03 & HiRes $90 \mathrm{~K}$ & Naida CI Q 70 \\
\hline$A A Q$ & 12,04 & Left & $\begin{array}{l}\text { Unknown; } \\
\text { congenital }\end{array}$ & - & 00,03 & $\begin{array}{l}\text { HiRes } 90 \mathrm{~K} \\
\text { Advantage }\end{array}$ & Naida CI Q 70 \\
\hline AAR & 08,10 & Right & $\begin{array}{l}\text { Unknown; family } \mathrm{Hx} \text {; } \\
\text { congenital }\end{array}$ & 00,10 & - & HiRes $90 \mathrm{~K}$ & Naida CI Q 70 \\
\hline AAS & 18,10 & Bilateral & Unknown & 15,00 & 16,03 & HiRes $90 \mathrm{~K}$ & Harmony \\
\hline $\mathrm{AAV}^{\dagger}$ & 13,10 & Bilateral & Unknown; congenital & 05,11 & 09,09 & HiRes $90 \mathrm{~K}$ & Naida CI Q 70 \\
\hline Mean (yrs, mo) & 14,08 & & & 04,06 & 06,05 & & \\
\hline $\mathrm{SD}(\mathrm{yrs})$ & 4.72 & & & 3.70 & 5.66 & & \\
\hline
\end{tabular}

*Uses Roger Pen at school.

$\dagger$ ASL/Total Communication is primary mode of communication.

and added to the program slots: (1) $100 \% \mathrm{TM}$, (2) UltraZoom $100 \%$ (ADM), (3) RM + TM 50/50 mixing ratio (RM50), (4) RM + TM 75/25 mixing ratio (RM75), and (5) RM 100\% (RM100). A ComPilot (Phonak, Zurik, Switzerland) neck-loop was worn by the participant to allow direct streaming of input from a clip-on, omnidirectional RM (Phonak) to the CI sound processor. The default level was used for the RM and ComPilot across all participants.

Before testing, all participants were familiarized with all target stimuli (two-syllable children's spondee words) used during the test trials. For the familiarization procedure, each token spondee word was presented at $65 \mathrm{~dB}$ SPL with the corresponding picture presented on a computer screen. The participant was instructed to repeat the spondee that was heard. Then, the picture was presented via the computer screen and the participant was asked to label it. Any word the participant was unable to consistently identify was not used during testing. Following familiarization, a practice test was presented using only the TM program. Participants did not need to meet set criteria to continue to the test conditions as the practice test was only used to familiarize the child with the test procedures.

For testing, the child faced a single-cone, Cambridge SoundWorks Center/Surround IV loudspeaker (Creative, Singapore) in a sound-attenuated booth, $1 \mathrm{~m}$ away, at $0^{\circ}$ azimuth with the RM placed $6^{\prime \prime}(15.24 \mathrm{~cm})$ below the center of the loudspeaker. Target stimuli consisted of a closed set of 25, two-syllable children's spondee words (Children's Spondee Word List; Auditec,
St. Louis, MO), spoken by a male talker at $0^{\circ}$ azimuth. Target spondees were recorded in a sound booth with a male talker who was instructed to place equal emphasis on each syllable of the spondee word. Root-mean-square equalization was done to facilitate accurate calibration. The root-mean-square values of each spondee were equalized by measuring the peak amplitude of the speech signals and then changing the amplitude to create equal amplitude across the various vowel sounds.

The competing background noise was 20-talker babble (Auditec), presented via a single-cone loudspeaker (Cambridge SoundWorks Center/Surround IV; Creative) placed at $180^{\circ}$ azimuth, $1 \mathrm{~m}$ behind the participant. The target spondee words and the 20-talker babble were calibrated to $60 \mathrm{~dB}$ SPL at $1 \mathrm{~m}$ (the location of the listener).

Preceding each target spondee was the carrier phrase "Ready, point to the..." also spoken by a male talker. In listening conditions with background babble, the interfering noise started before the carrier phrase and continued for approximately 1-2 sec following the target word (Johnstone and Litovsky, 2006). Following each stimulus presentation, a four-alternative forced-choice task was presented on a computer monitor to collect participant responses. Children used a computer mouse to click on the picture that best matched the target spondee word heard. A puzzle piece was presented for reinforcement following each response regardless if the participant's response was correct or not, such that one piece of the puzzle would appear until the condition was complete. Figure 1 depicts the test configuration. 
The TM and ADM are ear-level microphones on the CI processor, and therefore, are colocated with the listener ( $1 \mathrm{~m}$ from the loudspeaker presenting the target spondee words in front and $1 \mathrm{~m}$ from the loudspeaker presenting the interfering babble from behind). The RM was fastened $15.24 \mathrm{~cm}$ below the loudspeaker presenting the target spondee words and $2 \mathrm{~m}$ from the loudspeaker presenting the 20-talker babble.

All listening conditions, in the current study, started with the target stimulus presented at $70 \mathrm{~dB}$ SPL. The level of the target stimuli adaptively varied following a 3 down1 up algorithm to attain an SRT of 79.4\% correct (SRT80\%) (Levitt, 1971). The competing noise was presented at a fixed level of $60 \mathrm{~dB}$ SPL (for a detailed description of the children's realistic index of speech perception (CRISP) algorithm see Litovsky, 2004; 2005). An adaptive method that varies the level of the target speech to measure an SRT in fixed interfering noise has been used in pediatric HA research assessing FM and RM (e.g., Fabry, 1994; Lewis et al, 2004; Norrix et al, 2016); in research regarding children with bilateral CIs (e.g., Godar et al, 2004; Litovsky, Johnstone, et al, 2004; Litovsky, Parkinson, et al, 2004; Litovsky, Johnstone, and Godar, 2006, Litovsky, Johnstone, Godar, et al, 2006); with adult CI users (e.g., Gifford and Revit, 2010) and with adult HA users (e.g., Rodemerk and Galster, 2015). The SRT measurement used in the current study is clinically relevant. The Children's Spondee Word List is ubiquitous in pediatric clinics in North America, and audiologists understand how an SRT is measured clinically. An SRT in noise, in the clinical setting, is typically performed by lowering and raising the level of the spondees (as is done in quiet) while keeping the noise level fixed. Experimentally, measuring an SRT avoids the floor and ceiling effects obtained when measuring percent correct (Nilsson et al, 1994).
Table 2 shows the measured sound levels of the target stimuli and the background babble at the location of the various microphones used in this study. The levels for the target spondee words at the RM are higher than the level at the ear-level microphones because it is located much closer to the target loudspeaker at a distance recommended for actual use. Conversely, the level of the background babble at the RM is lower than the ear-level microphones because it is located twice the distance from the babble loudspeaker than the listener.

Estimates of SRT $80 \%$ were made following the methods used by Johnstone and Litovsky (2006). Briefly, a three-vector data matrix was created from each adaptive track. One vector contained all the levels visited during the adaptive track, the second vector contained the proportion correct at each level visited, and the third contained the total number of trials at each level visited. These data matrixes were fit to a logistic function and the inverse of the function taken at a specific probability level to estimate SRT at $80 \%$ accuracy (Johnstone and Litovsky, 2006). Level was then converted to SNR during noise tracks, and the same process used to estimate SRT $80 \%$ with reference to SNR instead of target level. To create group psychometric functions, all of the adaptive-track data matrixes for a specific listening condition were combined across participants.

Each SRT $80 \%$ was measured using the CRISP (Litovsky, 2004, 2005). CRISP was chosen because (1) it is an easy and rapid test that many children with $\mathrm{NH}$ or with $\mathrm{CI}$ can perform over a wide range of SNRs (Litovsky, 2004; 2005; Litovsky, Johnstone, and Godar, 2006; Litovsky, Johnstone, Godar, et al, 2006; Johnstone and Litovsky, 2006); (2) it avoids ceiling and floor effects by measuring SRT; and (3) a performance-intensity (PI) function can

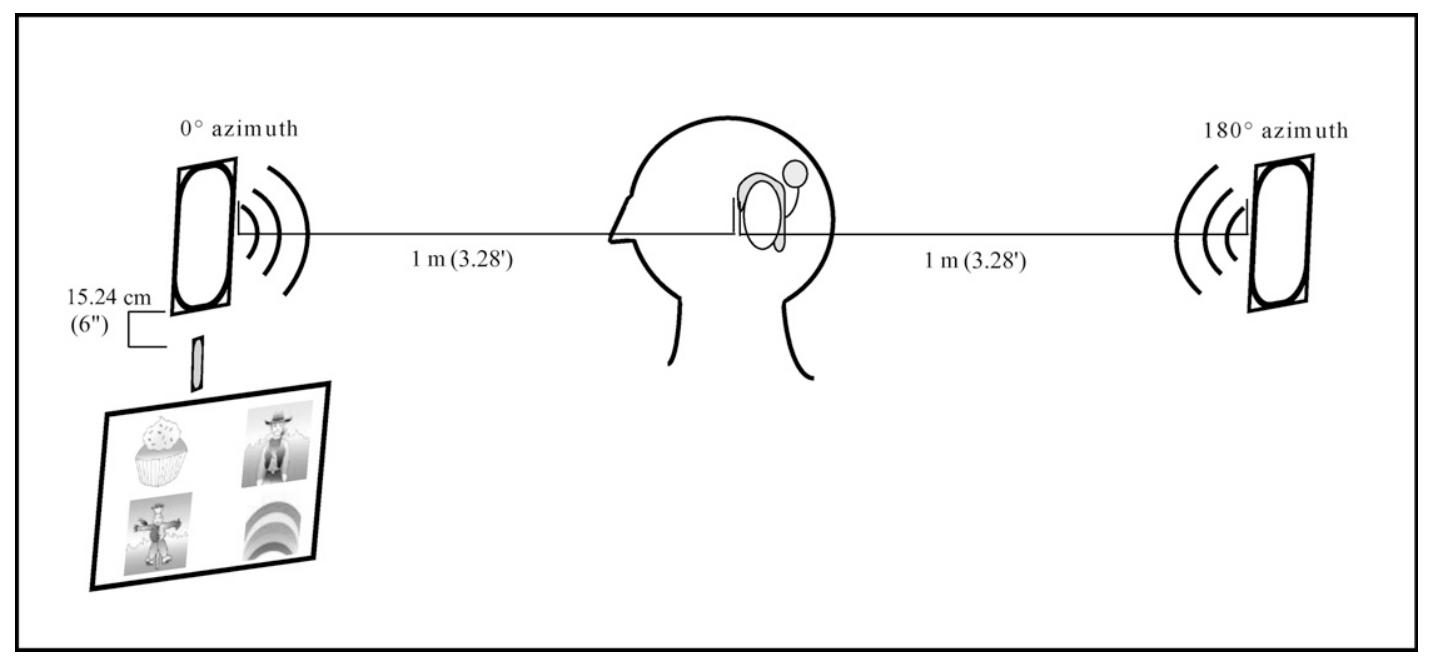

Figure 1. A schematic drawing of the test environment is shown. The listener was situated $1 \mathrm{~m}\left(3.28^{\prime}\right)$ from each loudspeaker. The front loudspeaker was located at $0^{\circ}$ azimuth and the rear loudspeaker was located at $180^{\circ}$ azimuth. The remote microphone was placed $15.24 \mathrm{~cm}$ $\left(6^{\prime \prime}\right)$ below the front loudspeaker. The monitor was placed in front of listener and the below the remote microphone at $0^{\circ}$ azimuth. 
Table 2. Microphone Distances and Measured Sound Levels

\begin{tabular}{lcccc}
\hline \multicolumn{4}{c}{ Speech Target and Noise Calibrated to $60 \mathrm{~dB}(\mathrm{~A})$ at $1 \mathrm{~m}$} \\
\hline Mic Option & $\begin{array}{c}\text { Distance from Speech } \\
\text { Target Loudspeaker }\end{array}$ & $\begin{array}{c}\text { Distance from Noise } \\
\text { Loudspeaker }\end{array}$ & $\begin{array}{c}\text { Starting Level (dBA) of Target at Mic } \\
(+10 \text { SNR @ Listener) }\end{array}$ & $\begin{array}{c}\text { Fixed Level (dBA) } \\
\text { of Noise at Mic }\end{array}$ \\
\hline TM & $1 \mathrm{~m}$ & $1 \mathrm{~m}$ & 70 & 60 \\
ADM & $1 \mathrm{~m}$ & $1 \mathrm{~m}$ & 70 & 60 \\
RM & $15.24 \mathrm{~cm}$ & $2 \mathrm{~m}$ & 84 & 54 \\
\hline
\end{tabular}

Note: $\mathrm{ADM}=$ adaptive directional mic; RM = remote mic; TM = T-mic

be created from the adaptive trials and reliable SRT estimates derived (Johnstone and Litovsky, 2006). These SRTs can be averaged across participant groups to compare various technologies and listening conditions.

Table 3 provides a concise summary of the seven test conditions used to measure SRT $80 \%$. Two test conditions measured SRT80\% in quiet (TM; RM50) and five test conditions measured SRT $80 \%$ with competing 20-talker babble (TM; ADM; RM50; RM75; and RM100). All seven listening configurations were randomly ordered across participants. All stimuli were routed through a Tucker-Davis Technologies (Alachua, FL) System III. Software for the stimulus presentation and data collection were operated via a custom MATLAB (MathWorks, Inc., Natick, MA) program (Litovsky, 2005; Johnstone and Litovsky, 2006) on a Dell Optiplex 9020 (Round Rock, TX) computer.

\section{RESULTS}

\section{Effect of Microhphone Technology in Quiet}

Figure $2 \mathrm{~A}$ and $\mathrm{B}$ show the group average PI functions for each listening condition in relation to chance performance (25\% accuracy) and the SRT $80 \%$. The results for the quiet condition are pictured in Figure 2A. Children with CI achieved $100 \%$ accuracy in quiet at $54 \mathrm{~dB}$ SPL with the RM50 and at $62 \mathrm{~dB}$ SPL with the TM. Overall, the use of the RM50 improved thresholds in quiet over use of the TM alone by an average of $6 \mathrm{~dB}$ for the children with CI. On average, children with $\mathrm{NH}$ had perfect performance (100\% accuracy) for spondee words at $38 \mathrm{~dB}$ SPL in quiet.
Figure $3 \mathrm{~A}$ and $\mathrm{B}$ show individual and mean group SRT80\% data. A between-subjects ANOVA was used to compare quiet SRT80\% between children with CI and children with $\mathrm{NH}$. When listening in quiet, CI participants showed significantly higher (poorer) SRT $80 \%$ with TM $\left(F_{[1,18]}=63.51, p<0.0001\right)$ or with $\operatorname{RM50}\left(F_{[1,18]}=27.77, p<0.0001\right)$ when compared with the $\mathrm{NH}$ group (see Figure 3A). Despite an average $6 \mathrm{~dB}$ improvement in SRT $80 \%$ with the RM50 when listening in quiet there was no significant difference in SRT80\% between TM and RM50 $\left(F_{[1,9]}=3.29, p=0.103\right)$ as revealed by repeated-measures ANOVA.

\section{Effect of Microphone Technology in Background Babble}

When background babble was introduced, the RM100 allowed children with $\mathrm{CI}$ to achieve perfect performance ( $100 \%$ correct) between +6 and +8 SNR. However, for children with CI, Perfect performance was not recorded at any SNR with any other microphone used (see Figure 2B). It was also noted that at a +10 SNR the RM100 showed PI roll-over that was not evident for any other microphone configuration tested.

At a 0 SNR when using TM alone, performance was poor particularly when compared with ADM or RM technology. At less favorable SNRs ( -20 to -5$)$, the use of RM was critical for children with CI and allowed them to match performance with peers with $\mathrm{NH}$ when the SNR was poorest. Interestingly, Children with $\mathrm{NH}$ showed the greatest listening advantage over children with CI when SNRs were most favorable. Children with $\mathrm{NH}$ had perfect performance (100\% correct) at all SNRs better than -5 (see Figure 2B).

Table 3. Summary of Test Conditions

\begin{tabular}{lllcc}
\hline Test & Condition & \multicolumn{1}{c}{ Noise } & \multicolumn{1}{c}{ Configuration } & Mixing Ratio \\
\hline 1 & Quiet TM & None & RM (Transmitter Off) + TM & TM 100\% \\
2 & Quiet RM50 & None & RM + TM & $50 / 50$ \\
3 & TM & 20 talker babble & RM (Transmitter Off) + TM & TM 100\% \\
4 & ADM & 20 talker babble & RM (Transmitter Off) + TM (Off) + ADM & ADM 100\% \\
5 & RM50 & 20 talker babble & RM + TM & $50 / 50$ \\
6 & RM75 & 20 talker babble & RM + TM & $75 / 25$ \\
7 & RM100 & 20 talker babble & RM + TM (Off) & RM 100\% \\
\hline
\end{tabular}

Note: $\mathrm{ADM}=$ adaptive directional microphone; $\mathrm{RM}$ = remote microphone; TM = T-mic. 
A

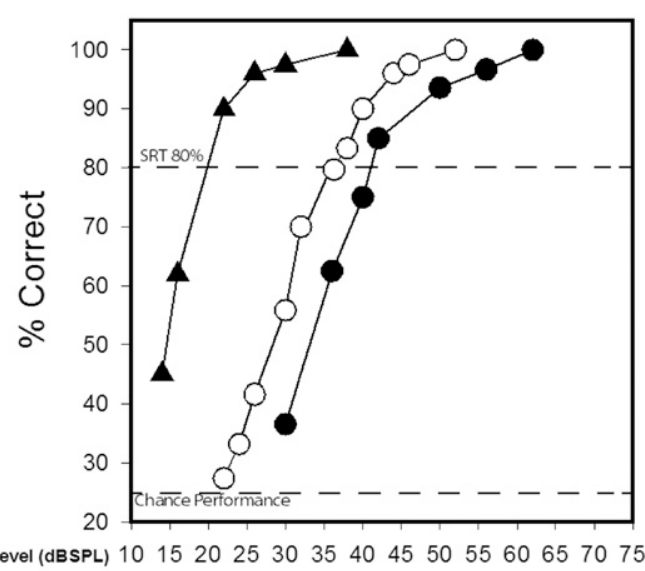

B

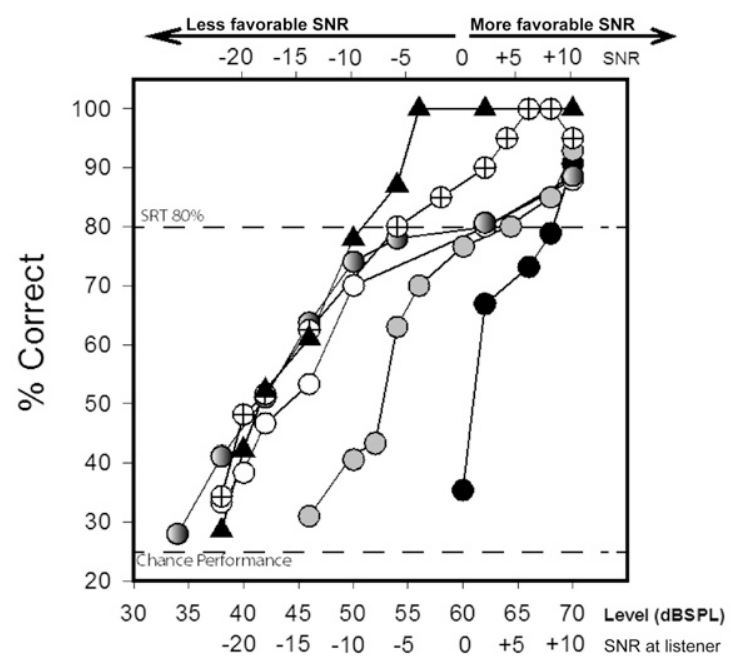

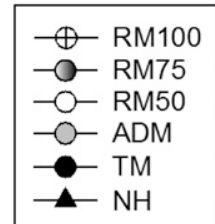

Figure 2. (A) Group performance-intensity functions in quiet and (B) group performance-intensity functions when background babble was present. Circles represent the performance of the CI group with various microphone technologies. The triangles show the performance of the $\mathrm{NH}$ group. Chance performance was set at $25 \%$ for a four-alternative forced choice for both groups. A SRT was estimated for $80 \%$ accuracy (SRT80\%). When background babble was present, the noise was presented at a fixed level of $60 \mathrm{dBA}$. An adaptive three-down, one-up algorithm (Litovsky, 2004; 2005) was used to measure thresholds in quiet and in noise.

The effect of the different microphones on individual SRT $80 \%$ is shown in Figure 3B. To assess the effect of microphone technology on SRT $80 \%$, a repeated measures ANOVA was done for the CI group. A significant main effect for microphone technology was found
$F_{[4,36]}=11.82, p<0.0001$. Post hoc repeated-measures, one-way ANOVA revealed how ADM and RM options significantly improved performance relative to TM alone. When listening in noise, statistically significant lower (better) SRT $80 \%$ where measured when the CI
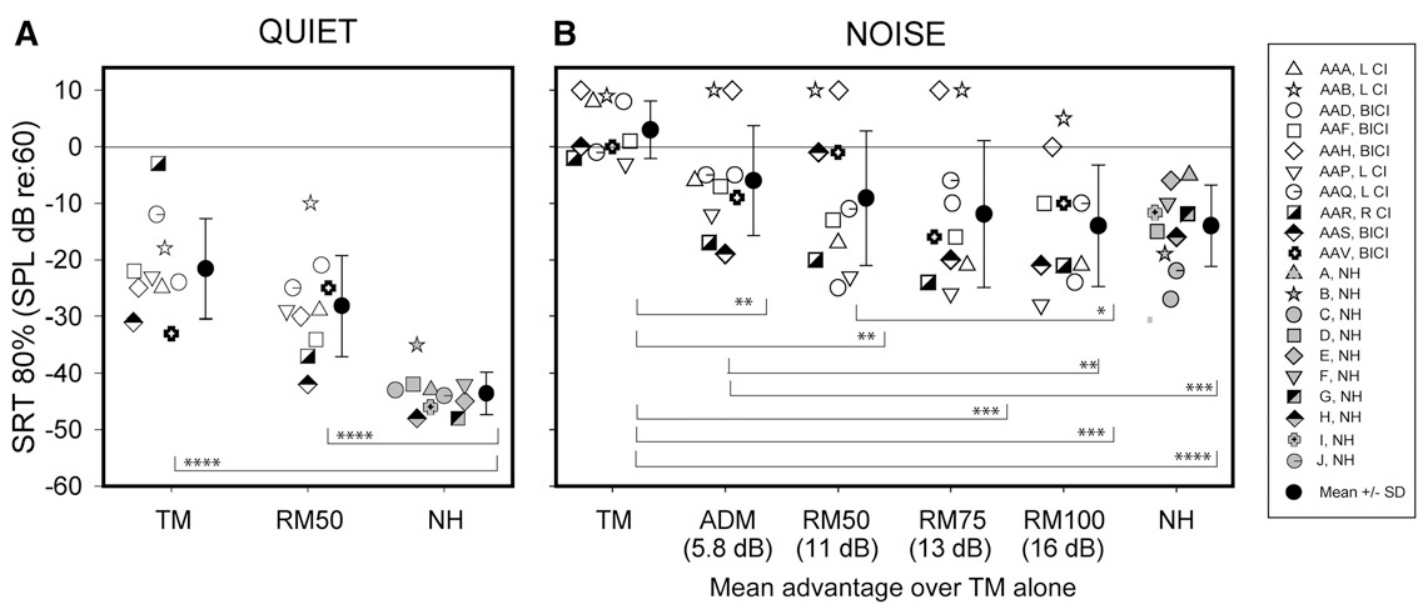

Figure 3. (A and B) SRT80\% for each individual participant for the quiet and noise listening conditions (respectively) as well as group means and standard deviations (black circles). The horizontal line at zero represents $60 \mathrm{dBHL}$, the sound level at $1 \mathrm{~m} / 3.28^{\prime}$ from the loudspeakers (the location of the listener). SRT $80 \%$ was significantly higher (poorer) for children with CI than children with NH in quiet and in noise when using the TM alone. Adding the ADM or RM provided a significant lowering (improvement) of SRT80\% for the CI group over use of the TM alone in noise (mean dB advantage in parentheses). When children with CI used the RM75 or RM100 in background babble, the SRT $80 \%$ was not statistically different than the group with $\mathrm{NH}$. 
group listened with $\mathrm{ADM}\left(F_{[1,9]}=18.52, p<0.005\right)$, RM50 $\left(F_{[1,9]}=10.3, p<0.01\right), \operatorname{RM} 75\left(F_{[1,9]}=21.58\right.$, $p<0.001)$, RM100 $\left(F_{[1,9]}=31.936, p<0.0001\right)$ when compared with performance with TM. In addition, SRT $80 \%$ was statistically significantly lower (better) when listening with RM75 $\left(F_{[1,9]}=11.23, p<0.01\right)$ and RM100 $\left(F_{[1,9]}=15.08, p<0.005\right)$ as compared with ADM. Finally, SRT $80 \%$ was statistically significantly lower (better) when using RM100 than $\operatorname{RM} 50\left(F_{[1,9]}=\right.$ $5.16, p<0.05)$. There was no significant difference in SRT $80 \%$ between RM75 and RM100 $\left(F_{[1,9]}=1.048\right.$, $p=0.33$ ).

To compare the effect of microphone options available to the CI group on SRT80\% as compared with children with $\mathrm{NH}$ a one-way, between-subjects ANOVA was per- formed. During the noise experiment, children with CI had statistically significantly greater (poorer) SRT $80 \%$ than children with $\mathrm{NH}$ when using $\operatorname{TM}\left(F_{[1,18]}=36.725\right.$, $p<0.0001)$ or $\mathrm{ADM}\left(F_{[1,18]}=4.668, p<0.05\right)$. There was, however, no significant difference in SRT $80 \%$ between children with $\mathrm{CI}$ and the NH group when the children with CI used RM50 $\left(F_{[1,18]}=1.226, p=0.283\right)$, $\operatorname{RM} 75\left(F_{[1,18]}=0.259, p=0.617\right)$, or $\operatorname{RM} 100\left(F_{[1,18]}=\right.$ $0.943, p=0.005$ ).

Figure 4 shows individual data depicting the improvement (in $\mathrm{dB}$ ) of the various microphone technologies and mixing ratios over TM alone. Participant data for the RM50 are rank ordered from greatest benefit to least. The same participant order is maintained for the other RM mixing ratios tested as well as for ADM.

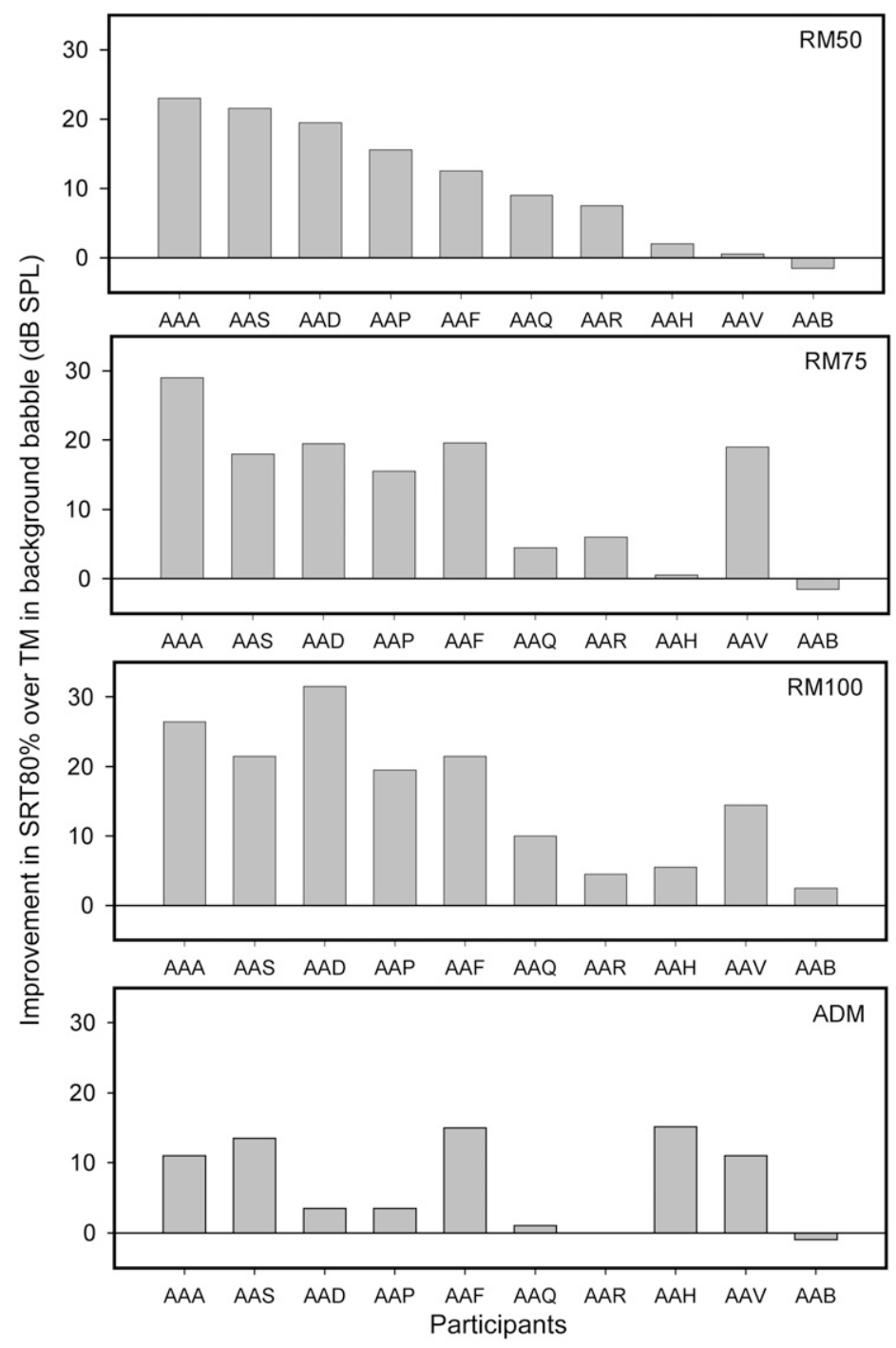

Figure 4. The average difference in performance in the CI group as compared with the control group with NH is shown. The horizontal line represents performance of children with NH. Bars that extend below the line show performance in the CI group that was poorer than the control group. Bars that extend above the line show performance in the CI group that was better than the control group. At a 0 SNR children with CI got $60 \%$ fewer words correct when using the TM alone than children with NH. The performance with TM alone was significantly poorer than the other microphone technologies tested at 0 SNR. At negative SNRs, the relative benefit of TM as compared with other microphone technologies could not be measured because average CI performance fell below chance levels when using TM alone. 
Although some children clearly benefited from any RM mixing ratio used, as compared with TM alone, others showed improvement with only one.

\section{Effect of SNR on Benefit}

To better understand spondee perception at various SNR, a difference score was computed by subtracting the average percent correct for the $\mathrm{NH}$ group from the CI Group at seven SNRs $(-20,-15,-10,-5,0$, $+5,+10)$. Figure 5 shows the average difference in spondee perception of children with CI as compared with children with $\mathrm{NH}$ (the horizontal flat line) across the seven SNRs. Statistical analysis of the difference scores, using mixed ANOVA revealed a statistically significant main effect for microphone configuration $F_{[4,36]}=4.733, p<0.005$; and $\mathrm{SNR} F_{[2,18]}=4.538, p<0.05$. A significant microphone $\mathrm{x}$ SNR interaction was also found $F_{[8,72]}=3.77, p<0.001$.

At SNRs less than zero, performance did not exceed chance when using TM alone. Post hoc one-way, repeated-measure ANOVA showed that performance was statistically significantly improved beyond ADM at -10 and -15 SNR with $\operatorname{RM} 75\left(F_{[1,9]}=7.018\right.$, $p<0.05 ; F_{[1,9]}=6.210, p<0.05$, respectively) and $\operatorname{RM} 100\left(F_{[1,9]}=6.320, p<0.05 ; F_{[1,9]}=6.210\right.$, $p<0.05$, respectively). At more favorable SNRs $(0$, $+5,+10)$ Post hoc one-way, repeated-measure ANOVA showed a statistically significantly improved performance at $0 \mathrm{SNR}$ with $\mathrm{ADM}\left(F_{[1,9]}=7.732 . p<0.05\right)$; $\operatorname{RM} 50\left(F_{[1,9]}=12.64, p<0.01\right)$; RM75 $\left(F_{[1,9]}=\right.$ 8.127, $p<0.05$; and RM100 $\left(F_{[1,9]}=13.675, p<\right.$ $0.005)$ as compared with TM alone. However, at +5 and +10 SNR, there were no significant differences in performance between the TM and ADM or RM technologies.

\section{DISCUSSION}

$\mathrm{T}$ he current study provides support for the use of microphone technology in children and adolescents who use CI. The use of RM technology, specifically, allowed the children with CI to maintain their best performance in recognizing familiar words across a wide range of SNRs at a short distance and to perform in some instances comparably to children with $\mathrm{NH}$. Although both RM75 and RM100 allowed for comparable best performance, many participants spontaneously reported that they did not like RM100 mixing ratio because of the inability to hear themselves speak. Also, the RM100 showed some evidence of degraded performance at the highest input levels for some childrenalthough none complained of degraded sound quality. Communication with Advanced Bionics confirmed that the RM output saturated at input levels above $75 \mathrm{dBA}$. It is not known how the nonlinearity of the RM at high levels of input impacts sound quality. Interestingly, the pattern of degraded performance at the highest input levels was not measured for any other microphone configuration tested. With all the other microphone configurations tested (TM, ADM, RM75, or RM50), children with CI typically showed best performance at the highest input level (best SNR) when background babble was present. Perhaps performance could be made even better with an RM that adaptively increased target gain at high input levels (e.g., the Roger microphone).

The results of this study provide evidence that both $\mathrm{ADM}$ and RM technology can improve speech recognition,

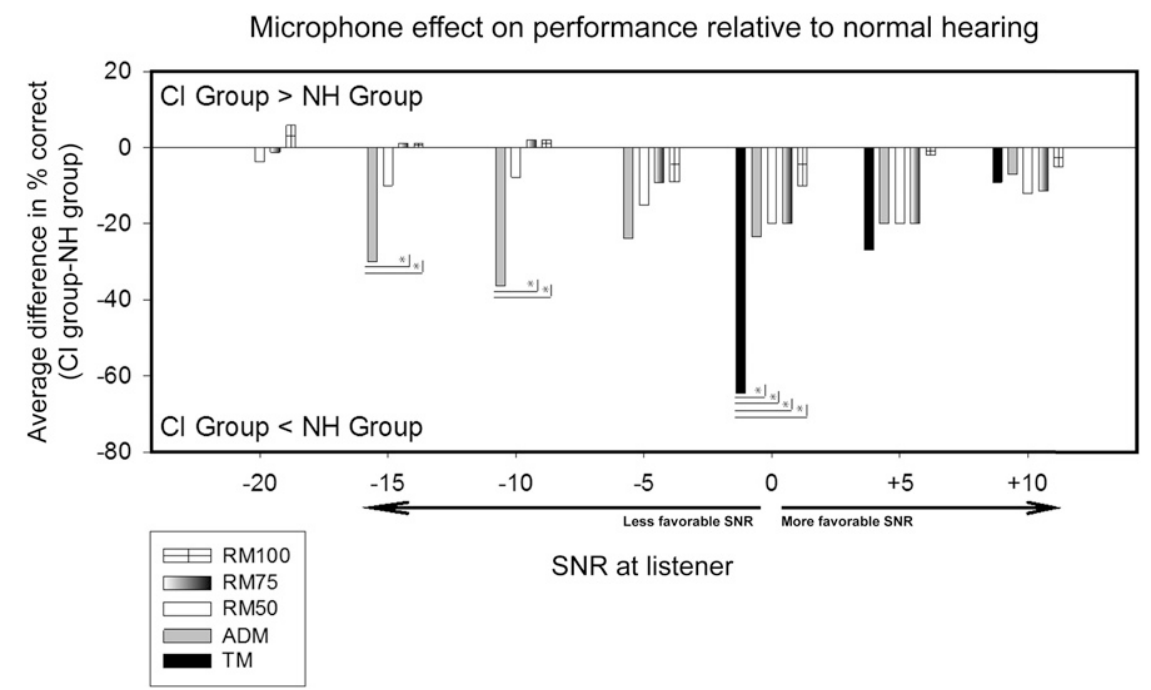

Figure 5. Individual data depicting the improvement (in $\mathrm{dB}$ ) of the various microphone technologies over TM alone are shown. Participant data for the RM50 are rank ordered from the greatest benefit to least. The participant order is maintained for the other RM mixing ratios tested as well as ADM. This allows one to better appreciate the benefit variability within- and between-subjects. Although some children clearly benefited from any RM mixing ratio as compared with TM alone, others showed improvement with only one. 
as compared with TM alone, even at a short distance $(1 \mathrm{~m} /$ $3.28^{\prime}$ ) from the talker when background noise is present. The significant difference found between children with CI and children with $\mathrm{NH}$ in quiet or in the presence of lowlevels of background noise, however, points to the real challenge facing those who seek to improve speech recognition in CI users. At best, most children with CI have hearing thresholds in quiet that are consistent with a mild sensorineural loss. Too often the impact of this mild hearing loss on speech recognition at close distances is not appreciated. Clinical tools that allow audiologists to predict audibility for a variety of speech spectra over different distances for children with CIs do not currently exist. Perhaps, programs developed to fit HAs on infants and toddlers could be adapted somehow for CI use: for example, the Situational Hearing Aid Response Profile (SHARP) (Stelmachowicz et al, 1993; Boys Town National Research Hospital, 2013). SHARP allows a clinician to create a visual representation of aided speech envelopes and to estimate the aided audibility index at various distances (e.g., when an infant/toddler is held at hip position - very close to talker; versus when the child is farther away at $4 \mathrm{~m} / 13.12$ ' from the talker). This type of program does not currently exist for use when evaluating/verifying/predicting the performance of CIs for children because SHARP depends on simulated real-ear measurements which are not applicable to CI technology. The current study suggests, however, that providing an estimate of the best possible CI audibility index (perhaps using behavioral thresholds, CI map data, and measurements of spread of excitation) might be of great value in clinical settings. Our study shows that children with mildly elevated thresholds secondary to CI implantation cannot match the performance of their $\mathrm{NH}$ peers at a short distance from a talker in quiet or at more favorable SNRs. Thus, the impact of the mildly elevated hearing thresholds, commonly associated with CIs and the positive impact of $\mathrm{ADM}$ and/or RM technology, on incidental learning might be considerably greater than currently thought: particularly in situations where the distance between the pediatric CI recipient and the talker is at least $3^{\prime}$.

Finally, this study has a few notable limitations. Inherent to most studies that test pediatric CI listeners, is the constraint of a small sample size. Only one CI manufacturer and one RM microphone arrangement (ComPilot with clip-on RM) were included. Other arrangements may provide more significant benefits. Testing was done at one short distance - performance may decline as distance increases for children with CI. Also, only recognizable spondee words were used for speech recognition purposes. One would predict that performance would decline with use of less familiar and more complex speech tokens. Finally, it is difficult to capture the dynamics of the classroom acoustics in a laboratory setting. In our study, we chose to keep the background noise at a fixed level and adaptively changed the level of the target talker. In reality, research has shown that the level of the background noise and the target talker (teacher) change throughout the course of the school day depending on the context. Future studies in actual classrooms may provide additional insight into the actual benefits afforded to children with CI by use of RM and ADM technology.

\section{CONCLUSION}

hildren with CIs should be given the option to use Adaptive Digital Microphone and Remote Microphone technology to improve performance in noise and in quiet. Although children with CI remain at a disadvantage as compared with $\mathrm{NH}$ children in quiet and more favorable SNRs, microphone technology can enhance performance for some children with CI to match that of NH peers in contexts with negative SNRs.

\section{REFERENCES}

Anderson KL, Goldstein H. (2004) Speech perception benefits of FM and infrared devices to children with hearing aids in a typical classroom. Lang Speech Hear Serv Sch 35(2):169-184.

Anderson KL, Goldstein H, Colodzin L, Iglehart F. (2005) Benefit of $\mathrm{S} / \mathrm{N}$ enhancing devices to speech perception of children listening in a typical classroom with hearing aids or a cochlear implant. J Educ Audiol 12:16-30.

Baker M, Buss E, Jacks A, Taylor C, Leibold LJ. (2014) Children's perception of speech produced in a two-talker background. $J$ Speech Lang Hear Res 57(1):327-337.

Boothroyd A, Inglehart F. (1998) Experiments with classroom FM amplification. Ear Hear 19(3):202-217.

Boys Town National Research Hospital. (2013) The Situational Hearing Aid Response Profile (SHARP) Version 7. User's Manual. Omaha, NE: Boys Town National Research Hospital.

Buechner A, Dyballa KH, Hehrmann P, Fredelake S, Lenarz T. (2014) Advanced beamformers for cochlear implant users: acute measurement of speech perception in challenging listening conditions. PLoS One 9(4):e95542.

Crandell CC. (1993) Speech recognition in noise by children with minimal degrees of sensorineural hearing loss. Ear Hear 14(3): $210-216$.

Crandell CC, Smaldino JJ. (2000) Classroom acoustics for children with normal hearing and with hearing impairment. Lang Speech Hear Serv Sch 31(4):362-370.

Dawson PW, Decker JA, Psarros CE. (2004) Optimizing dynamic range in children using the nucleus cochlear implant. Ear Hear 25(3):230-241.

Dawson PW, Mauger SJ, Hersbach AA. (2011) Clinical evaluation of signal-to-noise ratio-based noise reduction in Nucleus ${ }^{\circledR}$ cochlear implant recipients. Ear Hear 32(3):382-390.

Fabry DA. (1994) Noise reduction with FM systems in FM/EM mode. Ear Hear 15(1):82-86.

Finitzo-Hieber T, Tillman TW. (1978) Room acoustics effects on monosyllabic word discrimination ability for normal and hearingimpaired children. J Speech Hear Res 21(3):440-458. 
Geißler G, Arweiler I, Hehrmann P, Lenarz T, Hamacher V, Büchner A. (2015) Speech reception threshold benefits in cochlear implant users with an adaptive beamformer in real life situations. Cochlear Implants Int 16(2):69-76.

Gifford RH, Revit LJ. (2010) Speech perception for adult cochlear implant recipients in a realistic background noise: effectiveness of preprocessing strategies and external options for improving speech recognition in noise. J Am Acad Audiol 21(7):441-451, quiz 487-488.

Godar SP, Litovsky RY, Johnstone PM, Agrawal SS. (2004) In: Miyamoto R, ed. Cochlear Implant Plus Hearing Aid: Measuring Binaural Benefit in Children. International Congress Series. Vol. 1273. Elsevier, 219-222.

Hall JW 3rd, Grose JH, Buss E, Dev MB. (2002) Spondee recognition in a two-talker masker and a speech-shaped noise masker in adults and children. Ear Hear 23(2):159-165.

Hawkins DB. (1984) Comparisons of speech recognition in noise by mildly-to-moderately hearing-impaired children using hearing aids and FM systems. J Speech Hear Disord 49(4):409-418.

James CJ, Blarney PJ, Martin L, Swanson B, Just Y, Macfarlane D. (2002) Adaptive dynamic range optimization for cochlear implants: a preliminary study. Ear Hear 23(1, Suppl): 49S-58S.

Johnstone PM, Litovsky RY. (2006) Effect of masker type and age on speech intelligibility and spatial release from masking in children and adults. J Acoust Soc Am 120:2177-2189.

Knecht HA, Nelson PB, Whitelaw GM, Feth LL. (2002) Background noise levels and reverberation times in unoccupied classrooms: predictions and measurements. Am J Audiol 11(2):65-71.

Kolberg ER, Sheffield SW, Davis TJ, Sunderhaus LW, Gifford RH. (2015) Cochlear implant microphone location affects speech recognition in diffuse noise. $J$ Am Acad Audiol 26(1):51-58, quiz $109-110$

Levitt H. (1971) Transformed up-down methods in psychophysics. $J$ Acoust Soc Am 49:467-477.

Lewis DE. (1994) Assistive devices for classroom listening: FM systems. Am J Audiol 3:70-83.

Lewis DE. (2008) Trends in classroom amplification. Contemp Issues Commun Sci Disord 35:122-132.

Lewis DE, Eiten L. (2011) FM systems and communication access for children. In: Seewald R, Tharpe AM, eds. Comprehensive Handbook of Pediatric Audiology. San Diego, CA: Plural, pp. 553-564.

Lewis MS, Crandell CC, Valente M, Horn JE. (2004) Speech perception in noise: directional microphones versus frequency modulation (FM) systems. J Am Acad Audiol 15(6):426-439.

Litovsky RY. (2004) Method and system for rapid and reliable testing of speech intelligibility in children. J Acoust Soc Am 115:2699.

Litovsky RY. (2005) Speech intelligibility and spatial release from masking in young children. J Acoust Soc Am 117(5):3091-3099.

Litovsky RY, Johnstone PM, Godar SP. (2006) Benefits of bilateral cochlear implants and/or hearing aids in children. Int $J$ Audiol 45:(Suppl 1):S78-S91.

Litovsky RY, Johnstone PM, Godar S, Agrawal S, Parkinson A, Peters R, Lake J. (2006) Bilateral cochlear implants in children: localization acuity measured with minimum audible angle. Ear Hear 27(1):43-59.
Litovsky RY, Johnstone P, Parkinson A, Peters R, Lake J. (2004) In: Miyamoto R, ed. Bilateral Cochlear Implants in Children: Effect of Experience. International Congress Series. Vol. 1273. Elsevier, 451-454.

Litovsky RY, Parkinson A, Arcaroli J, Peters R, Lake J, Johnstone P, Yu G. (2004) Bilateral cochlear implants in adults and children. Arch Otolaryngol Head Neck Surg 130(5):648-655.

Lyberg Åhlander V, Pelegrín García D, Whitling S, Rydell R, Löfqvist A. (2014) Teachers' voice use in teaching environments: a field study using ambulatory phonation monitor. $J$ Voice $28(6)$ : 841.e5-841.e15.

Mauger SJ, Warren CD, Knight MR, Goorevich M, Nel E. (2014) Clinical evaluation of the Nucleus 6 cochlear implant system: performance improvements with SmartSound iQ. Int $J$ Audiol 53(8): $564-576$.

McCreery RW, Venediktov RA, Coleman JJ, Leech HM. (2012) An evidence-based systematic review of directional microphones and digital noise reduction hearing aids in school-age children with hearing loss. Am J Audiol 21(2):295-312.

Nelson HD, Bougatsos C, Nygren P; 2001 US Preventive Services Task Force (2008). Universal newborn hearing screening: systematic review to update the 2001 US Preventive Services Task Force recommendation. Pediatrics 122(1):e266-e276.

Nilsson M, Soli SD, Sullivan JA. (1994) Development of the hearing in noise test for the measurement of speech reception thresholds in quiet and in noise. J Acoust Soc Am 95(2): 1085-1099.

Norrix LW, Camarota K, Harris FP, Dean J. (2016) The effects of FM and hearing aid microphone settings, FM gain, and ambient noise levels on SNR at the tympanic membrane. J Am Acad Audiol 27(2):117-125.

Olsen WO. (1998) Average speech levels and spectra in various speaking/listening conditions: a summary of the Pearson, Bennett, \& Fidell (1977) report. Am J Audiol 7(2):21-25.

Pearsons KS, Bennett RL, Fidell S. (1977) Speech levels in various noise environments (Report No. EPA-600/1-77-025). Washington, DC: U.S. Environmental Protection Agency.

Pittman AL, Hiipakka MM. (2013) Hearing impaired children's preference for, and performance with, four combinations of directional microphone and digital noise reduction technology. $J$ Am Acad Audiol 24(9):832-844.

Plasmans A, Rushbrooke E, Moran M, Spence C, Theuwis L, Zarowski A, Offeciers E, Atkinson B, McGovern J, Dornan D, Leigh J, Kaicer A, Hollow R, Martelli L, Looi V, Nel E, Del Dot J, Cowan R, Mauger SJ. (2016) A multicentre clinical evaluation of paediatric cochlear implant users upgrading to the Nucleus(®) 6 system. Int J Pediatr Otorhinolaryngol 83:193-199.

Ricketts TA, Picou EM. (2013) Speech recognition for bilaterally asymmetric and symmetric hearing aid microphone modes in simulated classroom environments. Ear Hear 34(5):601-609.

Ricketts TA, Picou EM, Galster J. (2017) Directional microphone hearing aids in school environments: working toward optimization. J Speech Lang Hear Res 60(1):263-275.

Ricketts TA, Picou EM, Galster JA, Federman J, Sladen DP. (2010) Potential for directional hearing aid benefit in classrooms: field data. In: Seewald RC, Bamford JM, eds. A Sound Foundation through Early Amplification 2010: Proceedings of the Fifth International Conference. Stäfa, Switzerland: Phonak $A B$, $143-152$. 
Rodemerk KS, Galster JA. (2015) The benefit of remote microphones using four wireless protocols. J Am Acad Audiol 26:724-731.

Schafer EC, Thibodeau LM. (2006) Speech recognition in noise in children with cochlear implants while listening in bilateral, bimodal, and FM-system arrangements. Am J Audiol 15(2): $114-126$.

Schmidt P, Morrow SL. (2016) Hoarse with no name: chronic voice problems, policy and music teacher marginalisation. Music Educ Res 18:109-126.

Smaldino JJ, Crandell CC. (1999) Speech perception in the classroom. Volta Review 101(5):15-21.

Stelmachowicz PG, Mace AL, Kopun JG, Carney E. (1993) Longterm and short-term characteristics of speech: implications for hearing aid selection for young children. J Speech Hear Res 36(3):609-620.

Titze IR, Hunter EJ. (2015) Comparison of vocal vibration-dose measures for potential-damage risk criteria. J Speech Lang Hear Res 58(5):1425-1439.
Vroegop JL, Dingemanse JG, Homans NC, Goedegebure A. (2017) Evaluation of a wireless remote microphone in bimodal cochlear implant recipients. Int J Audiol 56(9):643-649; Early Online

Wolfe J, Duke M, Schafer E, Jones C, Rakita L. (2017) Evaluation of adaptive noise management technologies for school-age children with hearing loss. J Am Acad Audiol 28(5):415-435.

Wolfe J, Morais M, Schafer E. (2015) Improving hearing performance for cochlear implant recipients with use of a digital, wireless, remote-microphone, audio-streaming accessory. J Am Acad Audiol 26(6):532-539.

Wolfe J, Morais M, Schafer E, Agrawal S, Koch D. (2015) Evaluation of speech recognition of cochlear implant recipients using adaptive, digital remote microphone technology and a speech enhancement sound processing algorithm. J Am Acad Audiol 26(5): $502-508$.

Wolfe J, Schafer EC, Heldner B, Mülder H, Ward E, Vincent B. (2009) Evaluation of speech recognition in noise with cochlear implants and dynamic FM. J Am Acad Audiol 20(7):409-421. 